\title{
T1 measurements identify extracellular volume expansion in a genotyped hypertrophic cardiomyopathy population with and without left ventricular hypertrophy
}

Siddique Abbasi ${ }^{1 *}$, Ravi Shah ${ }^{1,2}$, Tomas G Neilan ${ }^{1,2}$, Bobby Heydari ${ }^{1}$, Yucheng Chen ${ }^{1}$, Michael Jerosch-Herold ${ }^{1}$, Raymond Y Kwong ${ }^{1}$, Carolyn $\mathrm{Ho}^{1}$

From 16th Annual SCMR Scientific Sessions

San Francisco, CA, USA. 31 January - 3 February 2013

\section{Background}

Myocardial fibrosis is a hallmark of hypertrophic cardiomyopathy (HCM) and may contribute to arrhythmias and heart failure. Sarcomere mutations appear to induce profibrotic changes before left ventricular hypertrophy (LVH) develops. Measuring T1 relaxation times with contrast cardiac magnetic resonance (CMR) allows robust quantification of the cardiac extracellular volume (ECV) and noninvasive assessment of diffuse myocardial fibrosis.

\section{Methods}

A genotyped HCM population underwent contrast CMR with measurement of T1. Subjects included sarcomere mutation carriers with $\mathrm{LVH}(\mathrm{G}+/ \mathrm{LVH}+, \mathrm{n}=37)$ and without LVH $(\mathrm{G}+/ \mathrm{LVH}-, \mathrm{n}=30)$; HCM patients without mutations (sarcomere-negative HCM, $\mathrm{n}=11$ ); and mutation-negative healthy controls $(\mathrm{n}=10)$. Concurrent echocardiography and serum biomarkers of collagen synthesis, hemodynamic stress, and myocardial injury were available in a subset.

\section{Results}

Late gadolinium enhancement (LGE) was present in $>60 \%$ of overt HCM patients but absent from G+/LVHsubjects. Compared to controls, ECV was increased in patients with overt HCM, as well as G+/LVH- mutation

Table 1 CMR Metrics of Fibrosis and Serum PICP levels

\begin{tabular}{|c|c|c|c|c|c|c|}
\hline & Control $\mathrm{N}=10$ & $\begin{array}{l}\text { p-value* Control vs } \\
\text { Preclinical }\end{array}$ & $\begin{array}{c}\text { Preclinical HCM } \\
\qquad \mathrm{N}=30\end{array}$ & $\begin{array}{c}\text { p-value* Preclinical vs } \\
\text { Overt }\end{array}$ & $\begin{array}{l}\text { Overt HCM } \\
\qquad N=37\end{array}$ & $\begin{array}{c}\text { p-value }{ }^{*} \text { Control vs } \\
\text { Overt }\end{array}$ \\
\hline ECV (range) & $\begin{array}{r}0.26 \pm 0.01 \\
(0.24-0.31)\end{array}$ & $<0.001$ & $\begin{array}{c}0.33 \pm 0.01(0.23- \\
0.38)\end{array}$ & $<0.001$ & $\begin{array}{r}0.37 \pm 0.01 \\
(0.31-0.51)\end{array}$ & $<0.001$ \\
\hline ECV, excluding LGE & $0.26 \pm 0.01$ & $<0.001$ & $0.33 \pm 0.01$ & $<0.001$ & $0.37 \pm 0.01$ & $<0.001$ \\
\hline $\begin{array}{l}\text { LGE present, \% } \\
\text { (\#yes / \#no) }\end{array}$ & $0 \%(0 / 10)$ & & $0 \%(0 / 29)$ & & $78.4 \%(29 / 8)$ & \\
\hline LGE, g & 0 & 0.8 & 0 & 0.004 & $16.7 \pm 4.9$ & 0.003 \\
\hline LGE, \% LV mass & 0 & 0.7 & 0 & 0.0006 & $\begin{array}{l}7.76 \pm 1.96 \\
(0.9-44.6 \%)\end{array}$ & 0.001 \\
\hline $\mathrm{PICP}, \mu \mathrm{g} / \mathrm{L}$ & $63.08 \pm 4.19$ & $<0.001$ & $83.81 \pm 4.39$ & 0.035 & $108.04 \pm 9.81$ & $<0.001$ \\
\hline
\end{tabular}

Data are presented as means adjusted for family relations and age \pm standard error * $p$ values $<0.017$ are statistically significant and adjusted for age and family relations ECV = extracellular volume; $\mathrm{LGE}=$ late gadolinium enhancement; $\mathrm{PICP}=$ carboxy-terminal propeptide of procollagen type I

'Department of Cardiovascular Medicine, Brigham and Women's Hospital/

Harvard Medical School, Boston, MA, USA

Full list of author information is available at the end of the article

(c) 2013 Abbasi et al; licensee BioMed Central Ltd. This is an Open Access article distributed under the terms of the Creative Commons 


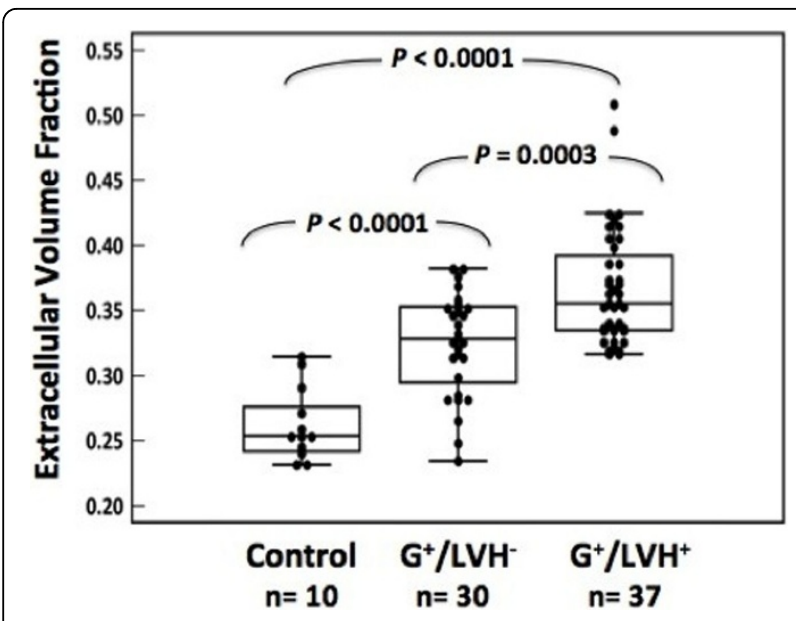

Figure $\mathbf{1}$ ECV is significantly increased in HCM sarcomere mutation carriers both with and without LVH Compared to normal controls, ECV was $25 \%$ in $\mathrm{G}+/ \mathrm{LVH}$ - subjects and $42 \%$ higher in $\mathrm{G}+/ \mathrm{LVH}+$ HCM patients ( $p<0.001$ for all comparisons to controls). ECV was further increased by $13 \%$ in overt HCM compared to G+/LVHsubjects $(p=0.0003)$.

carriers $(\mathrm{ECV}, 0.37 \pm 0.01,0.33 \pm 0.01,0.26 \pm 0.01$ in $\mathrm{G}$ $+/ \mathrm{LVH}+, \mathrm{G}+/ \mathrm{LVH}-$, controls, respectively, $\mathrm{P}<0.001)$. ECV was correlated with NT-proBNP levels $(r=0.61$, $\mathrm{P}<0.001)$ and global E' velocity $(\mathrm{r}=-0.48, \mathrm{P}<0.001)$. ECV and LGE were higher in sarcomeric HCM than sarcomere-negative HCM.

\section{Conclusions}

Myocardial ECV is increased not only in sarcomere mutation carriers with overt HCM, but also those with normal LV wall thickness. These data provide further evidence that fibrotic remodeling is triggered early in disease pathogenesis. Assessing ECV may help characterize the development of HCM-induced myocardial fibrosis, ultimately supporting novel strategies to modify disease by targeting interstitial fibrosis.

\section{Funding}

This work was supported by grants from the National Institutes of Health (CYH and RYK).

\section{Author details}

'Department of Cardiovascular Medicine, Brigham and Women's Hospital/ Harvard Medical School, Boston, MA, USA. ${ }^{2}$ Cardiology, Massachusetts General Hospital, Boston, MA, USA.

Published: 30 January 2013

doi:10.1186/1532-429X-15-S1-O21

Cite this article as: Abbasi et al:: T1 measurements identify extracellular volume expansion in a genotyped hypertrophic cardiomyopathy population with and without left ventricular hypertrophy. Journal of Cardiovascular Magnetic Resonance 2013 15(Suppl 1):O21.
Submit your next manuscript to BioMed Central and take full advantage of:

- Convenient online submission

- Thorough peer review

- No space constraints or color figure charges

- Immediate publication on acceptance

- Inclusion in PubMed, CAS, Scopus and Google Scholar

- Research which is freely available for redistribution 